\title{
Intrinsic spontaneous activity and $\beta$-adrenoceptor-mediated tubal dilatation affect ovum transport in the oviduct of the cow
}

\author{
M. Isla, G. Costa, A. García-Pascual, D. Triguero and A. García-Sacristán \\ Departamento de Fisiología Animal, Facultad de Veterinaria, Universidad Complutense de Madrid, \\ 28040-Madrid, Spain
}

\begin{abstract}
Summary. Oviducts of cows were obtained during the proliferative and secretory phases of the oestrous cycle (determined by macroscopic appearance of the ovaries). Consistently higher frequencies of contraction were observed in the isthmus than in the ampulla, whereas no significant difference was observed between longitudinal and circular specimens, or throughout the oestrous cycle. Basal activity was inhibited by removal of extracellular $\mathrm{Ca}^{2+}$ and by verapamil $\left(10^{-5} \mathrm{M}\right)$. Addition of $\mathrm{Ca}^{2+}$ restored activity in the first case, but not in the second. Administration of various adrenoceptor agonists and antagonists revealed that the responses of the longitudinal and circular smooth muscles were primarily mediated by $\beta$-adrenoceptors $\left(\beta_{2}>\beta_{1}\right)$, while the $\alpha$-adrenoceptor-mediated contractions ( $\alpha_{2}$-subtype) were masked by the marked $\beta$-adrenergic dominance. The results support the concept that the significance of adrenergic nerves in the cow oviduct may be to produce relaxation rather than contraction; the combined $\beta_{1}$ - and $\beta_{2}$-adrenoceptor-mediated tubal dilatation and the intrinsic spontaneous activity seem to be the main factors affecting ovum/embryo transport throughout the oviduct in cows.
\end{abstract}

Keywords: adrenoceptors; cattle; oviduct; smooth muscle; spontaneous activity

\section{Introduction}

The oviduct is engaged in various processes essential for reproduction. Within the ampulla the egg is transported in a complex to-and-fro movement (Verdugo et al., 1976) influenced by the motility of the cilia and secondarily by smooth muscle activity (Arnold \& Shorey, 1985). The tube-locking mechanism of the ampullary-isthmic junction (AIJ), as well as the rapid passage into the uterus, seem to be effected by tubular muscular activity (Anand \& Guha, 1978), under the control of the sympathetic nervous system (Brundin, 1965; Pauerstein et al., 1974).

The adrenergic response has been analysed in several animal species. $\alpha$-Adrenergic receptors predominate in the oviduct musculature of the rabbit (Howe \& Black, 1973) and pig (RodriguezMartinez, 1984). However, in the human Fallopian tube, $\beta$-adrenoceptors predominate throughout the menstrual cycle, and stimulation of adrenergic nerves would therefore produce relaxation more than contraction (Samuelson \& Sjöstrand, 1986). However, the physiological function of genital tract $\beta$-receptors is controversial, because noradrenaline, which is by far the predominant catecholamine in the myosalpinx, is among the weakest of catecholamines in stimulating $\beta$-adrenoceptors (Jansen, 1984).

This discrepancy of results among species has motivated our study of the characteristics of the spontaneous activity of the oviduct of the cow and the influence of adrenergic receptors over it. Our aim was to clarify the possible role of these receptors in regulating ovum/embryo transport. 


\section{Materials and Methods}

Tissues. Oviducts with their corresponding ovaries from non-pregnant sexually mature cows were collected at the local slaughterhouse and transported to the laboratory in ice-cold Krebs' solution (see below) within 30 min. Reproductive status, determined by macroscopic examination of the ovaries, was designated as proliferative or secretory according to Rosenberger (1969).

Oviducts were transferred to a Petri dish containing Krebs' solution at room temperature, and carefully dissected from adjacent tissues. Longitudinal strips ( $10 \mathrm{~mm}$ long, $2-4 \mathrm{~mm}$ width) and rings ( $3-4 \mathrm{~mm}$ width) from the middle portions of the ampulla (longitudinal and circular ampulla) and isthmus (longitudinal and circular isthmus) were prepared according to the methods previously described by Gimeno et al. (1984) for pigs, and Helm et al. (1982a) for human tissue.

Preparations were mounted in $30-\mathrm{ml}$ organ baths containing Krebs' solution at $37^{\circ} \mathrm{C}$ bubbled with a mixture of $5 \% \mathrm{CO}_{2}$ and $95 \% \mathrm{O}_{2}$.

Attachment to the bath and connections to the transducer (Grass FTO3C) were by direct silk ties for longitudinal strips, or by stainless-steel hooks for circular ones. Changes in isometric force were recorded on a Grass polygraph (model 79D).

The longitudinal and circular ampullary and isthmic preparations were given initial passive tensions of $1.5 \mathrm{~g}, 1 \mathrm{~g}$, $1 \mathrm{~g}$ and $0.75 \mathrm{~g}$ respectively. At these tensions, determined in previous experiments, the preparations showed uniform rhythmic spontaneous activity.

After equilibration (60-90 min), the frequency of spontaneous contractions was measured during a 5-min period. Cumulative dose-response curves were performed for the different agonists, expressing the effect of each agonist as a percentage of the maximum response in each curve. Antagonists were added $20 \mathrm{~min}$ before the next dose-response test, and their effects were expressed as a percentage of the control, i.e. with the agonist.

Statistics and calculations. The drug concentration eliciting half maximum contraction $\left(\mathrm{EC}_{50}\right)$ or relaxation $\left(\mathrm{IC}_{50}\right)$ was determined graphically for each curve by linear interpolation. Values are expressed as the mean \pm s.e.m., and statistical analyses were performed by Student's $t$ test and analysis of variance. The level of statistically significant difference was considered to be $P<0.05$.

Solutions. Normal Krebs' solution had the following composition (mmol/1): $\mathrm{NaCl} 119, \mathrm{NaHCO}_{3} 24 \cdot 9, \mathrm{KCl} 4 \cdot 6$, $\mathrm{MgCl}_{2}\left(6 \mathrm{H}_{2} \mathrm{O}\right) 1 \cdot 2, \mathrm{KH}_{2} \mathrm{PO}_{4} 1 \cdot 4, \operatorname{EDTA}\left(2 \mathrm{H}_{2} \mathrm{O}\right) 0.0027$, glucose $1 \mathrm{I}$, and $\mathrm{CaCl}_{2} 1 \cdot 5$. In experiments involving a calcium-free solution, $\mathrm{CaCl}_{2}$ was omitted from the normal $\mathrm{Krebs}$ ' solution and replaced with $0.01 \mathrm{mM}$-EGTA.

Substances. The following substances were purchased: D-L-Noradrenaline $\mathrm{HCl}$ (Serva Feinbiochemica $\mathrm{GmbH} \&$ Co., Heidelberg, FRG), phenylephrine HCl (Sigma Chemical Co., St. Louis, MO), B-HT-920 (Dr K. Thomae GmbH, Biberach an der Riss, FRG), isoprenaline sulphate (C. H. Boehringer Sohn, Ingelheim am Rhein, FRG), salbutamol sulphate (Glaxo Labs., Ltd, Greenford, Middlesex, UK), phenoxybenzamine $\mathrm{HCl}$ (Smith Kline \& French, Welwyn Garden City, UK), yohimbine $\mathrm{HCl}$ (Sigma), propranolol $\mathrm{HC}$ and practolol (ICI-Pharma Arzneimittelwerk, Plankstadt, FRG), and butoxamine $\mathrm{HCl}$ (The Wellcome Foundation, London, UK).

\section{Results}

All preparations exhibited a standard rhythmic motility with uniform and symmetrical contractions throughout the experiments (Fig. 1). Isthmic preparations showed significantly higher frequencies of contraction $(P<0.01)$ than did the ampullary preparations. However, no significant differences between frequencies of contraction in longitudinal and circular preparations from the ampulla and isthmus, in the proliferative or secretory phases of the oestrous cycle, could be detected. No cyclical difference in the frequency of contraction could be observed in any of the 4 preparations studied (Table 1).

Calcium withdrawal from the solution abolished in approximately $20 \mathrm{~min}$ the spontaneous activity in all 4 preparations. Subsequent administration of cumulative concentrations of calcium, caused the quick recuperation of the activity, even with minimum quantities of this ion $(0.5 \mathrm{~mm}-$ $\mathrm{Ca}^{2+}$ ) (Fig. 2a). Verapamil $\left(10^{-5} \mathrm{M}\right)$ completely inhibited the spontaneous activity in a few minutes; the motility of the oviduct was not restored with the addition of increasing concentrations of calcium (Fig. 2b).

Noradrenaline $\left(10^{-7}-10^{-4} \mathrm{M}\right)$ elicited dose-dependent relaxations in all 4 preparations studied (with an order of potency of longitudinal ampulla $>$ circular isthmus $>$ circular ampulla $>$ longitudinal isthmus). Phenoxybenzamine $\left(10^{-6} \mathrm{M}\right)$ shifted to the left $(P<0.01)$ the relaxing control 
Table 1. Frequency of spontaneous contractions in oviduct preparations of cattle in the proliferative and secretory phases of the oestrous cycle

\begin{tabular}{lcc}
\hline & \multicolumn{2}{c}{ Contractions/min } \\
\cline { 2 - 3 } Preparation & Proliferative phase & Secretory phase \\
\hline Ampulla & $4 \cdot 82 \pm 0.4$ & $5 \cdot 61 \pm 0.3$ \\
Longitudinal & $(18)$ & $(18)$ \\
Circular & $4 \cdot 73 \pm 0.2$ & $5 \cdot 12 \pm 0.3$ \\
Isthmus & $(18)$ & $(18)$ \\
$\quad$ Longitudinal & $6.72 \pm 0.2^{*}$ & $6.91 \pm 0.3^{*}$ \\
Circular & $(18)$ & $(18)$ \\
& $7.59 \pm 0.3^{*}$ & $6.59 \pm 0.4^{*}$ \\
& $(18)$ & $(18)$ \\
\hline
\end{tabular}

Values are mean \pm s.e.m. for the no. of preparations in parentheses. ${ }^{*} P<0.01$ compared with same muscle type in the ampulla.

curves of noradrenaline. Addition of isoprenaline $\left(10^{-8}-10^{-5} \mathrm{M}\right)$ evoked a dose-dependent relaxing effect, with no significant difference (expressed as $-\log \mathrm{IC}_{50}$ values) between preparations. Propranolol $\left(10^{-6} \mathrm{M}\right)$ minimized the relaxing effects of isoprenaline $(P<0.001)$. Practolol $\left(10^{-5} \mathrm{M}\right)$, a selective $\beta_{1}$-adrenoceptor antagonist, slightly modified the control curves of isoprenaline $(P<0.05)$, but prior administration of butoxamine $\left(10^{-5} \mathrm{M}\right)$, a $\beta_{2}$-adrenoceptor blocker, substantiaily reduced $(P<0.001)$ the effect of isoprenaline. Salbutamol $\left(10^{-8}-10^{-5} \mathrm{M}\right)$, a selective $\beta_{2}$ agonist, mimicked the isoprenaline-induced effect in all 4 preparations tested. Pretreatment with butoxamine $\left(10^{-5} \mathrm{M}\right)$ abolished significantly $(P<0.001)$ the inhibitory effects of salbutamol (Table 2).

The response to noradrenaline was reversed by $10^{-6} \mathrm{M}$-propanolol, and all tubal preparations responded with dose-dependent contractions (Table 3). Practolol $\left(10^{-5} \mathrm{M}\right)$ mimicked this effect of propanolol when administered before a single dose of noradrenaline $\left(10^{-5} \mathrm{M}\right)$ (Fig. 3). To clarify the $\alpha$-adrenergic component of noradrenaline, phenylephrine and B-HT-920 were used as selective $\alpha_{1}$ and $\alpha_{2}$ agonists, respectively. Phenylephrine $\left(10^{-7}-10^{-4} \mathrm{M}\right)$ had no effect on any of the preparations studied. B-HT-920 originated dose-dependent contractile effects when added to the organ bath at cumulative concentrations of $10^{-7}$ to $5 \times 10^{-4} \mathrm{M}$, with no significant difference (expressed as $-\operatorname{logEC} \mathrm{C}_{50}$ values) between preparations. The contractile effect of B-HT-920 was selectively blocked by yohimbine $\left(10^{-5} \mathrm{M}\right)(P<0.001)$ (Table 3$)$.

\section{Discussion}

Schilling (1962) has described the distribution of muscle layers in ungulates as spirals around the tube, which are less extended in the ampulla than in the isthmus. The fact that the same type of uniform rhythmic spontaneous activity was found in all tubal preparations (Fig. 1), and that no significant difference in frequency of contraction could be observed between longitudinal and circular preparations (Table 1), could be, from a functional point of view, in accordance with Schilling's (1962) theory. The different frequencies of contraction observed between the ampullary and isthmic preparations (Table 1) could be related to differentiated smooth muscle cell membrane properties of these two segments, as discussed by Lindblom et al. (1979b) for the human Fallopian tube. Nevertheless, conclusions from the study of frequencies of contraction should be drawn with caution, since the smooth muscle of the oviduct responds actively to stretch (Arjamaa, 1984; Samuelson \& Sjöstrand, 1986). 
LA Pro

LA Sec

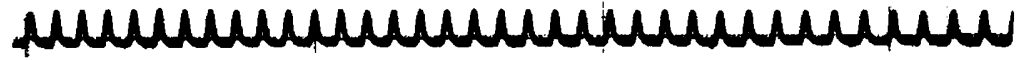

CA Pro

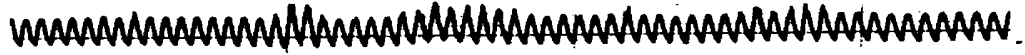

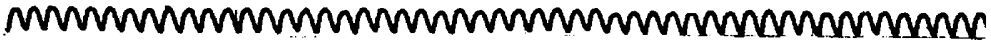

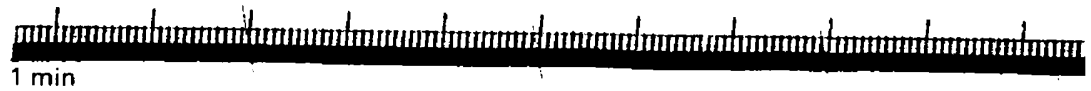

LI Pro

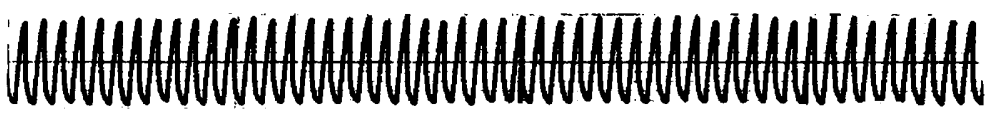

니 Sec

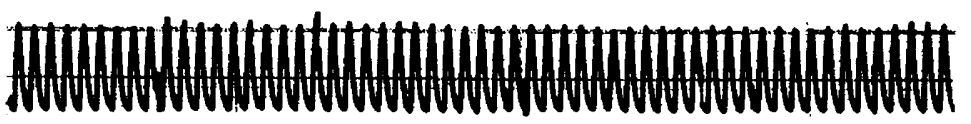

CI Pro

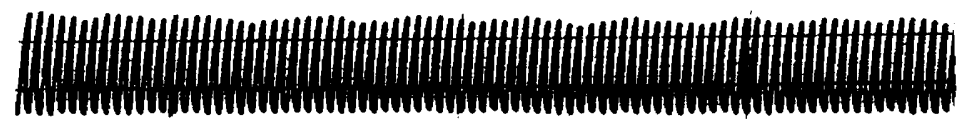

$\mathrm{Cl} \mathrm{Sec}$

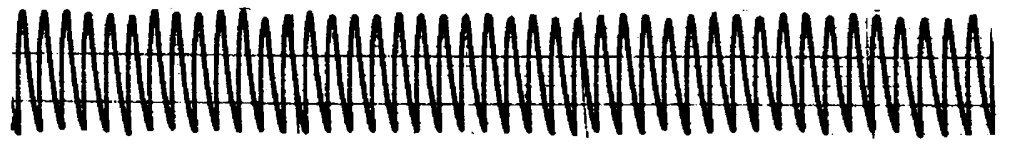

Fig. 1. Spontaneous activity of longitudinal ampulla (LA), circular ampulla (CA), longitudinal isthmus (LI) and circular isthmus (CI) preparations during the proliferative (Pro) and secretory $(\mathrm{Sec})$ phases of the oestrous cycle in cattle. 

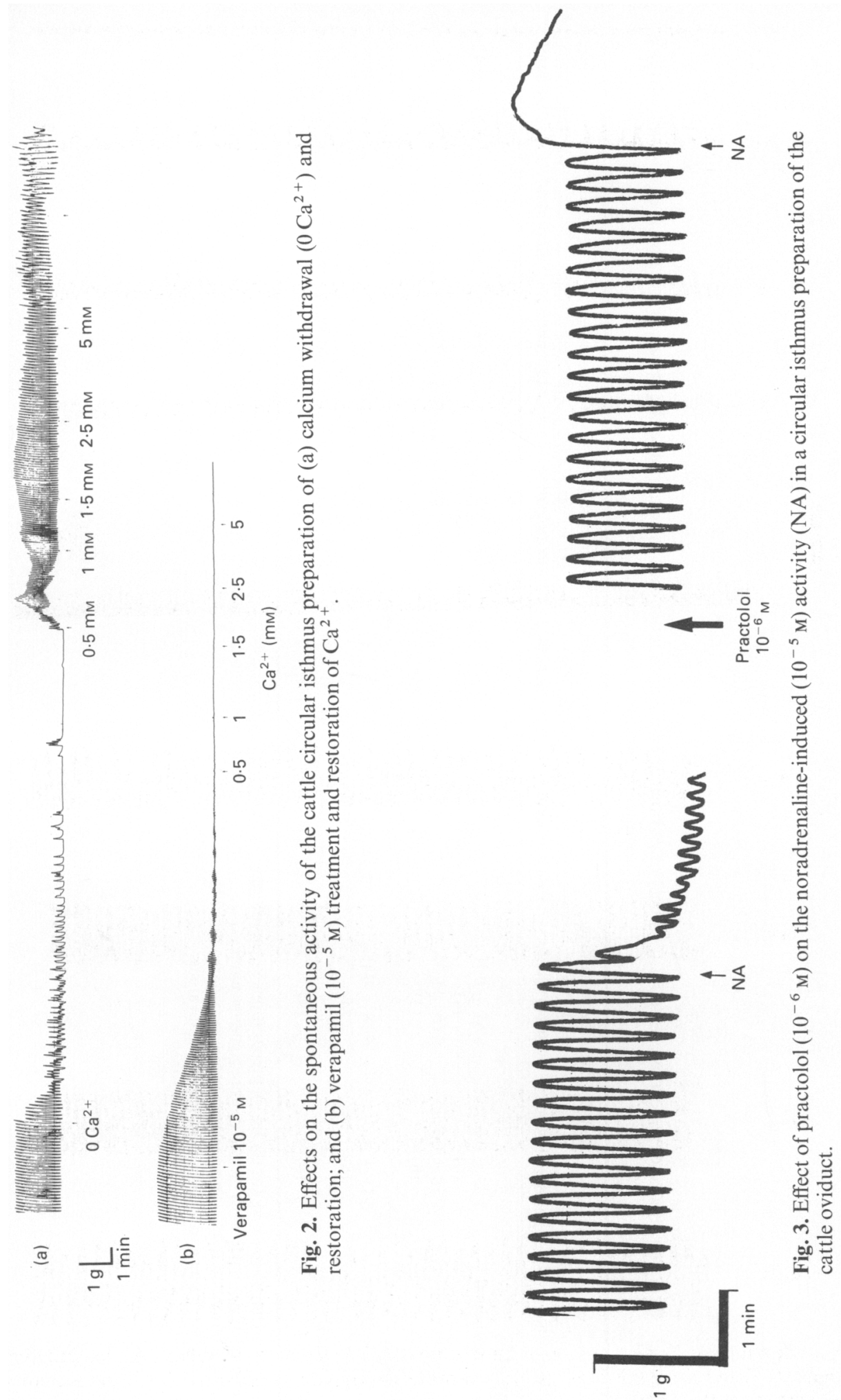
M. Isla et al.

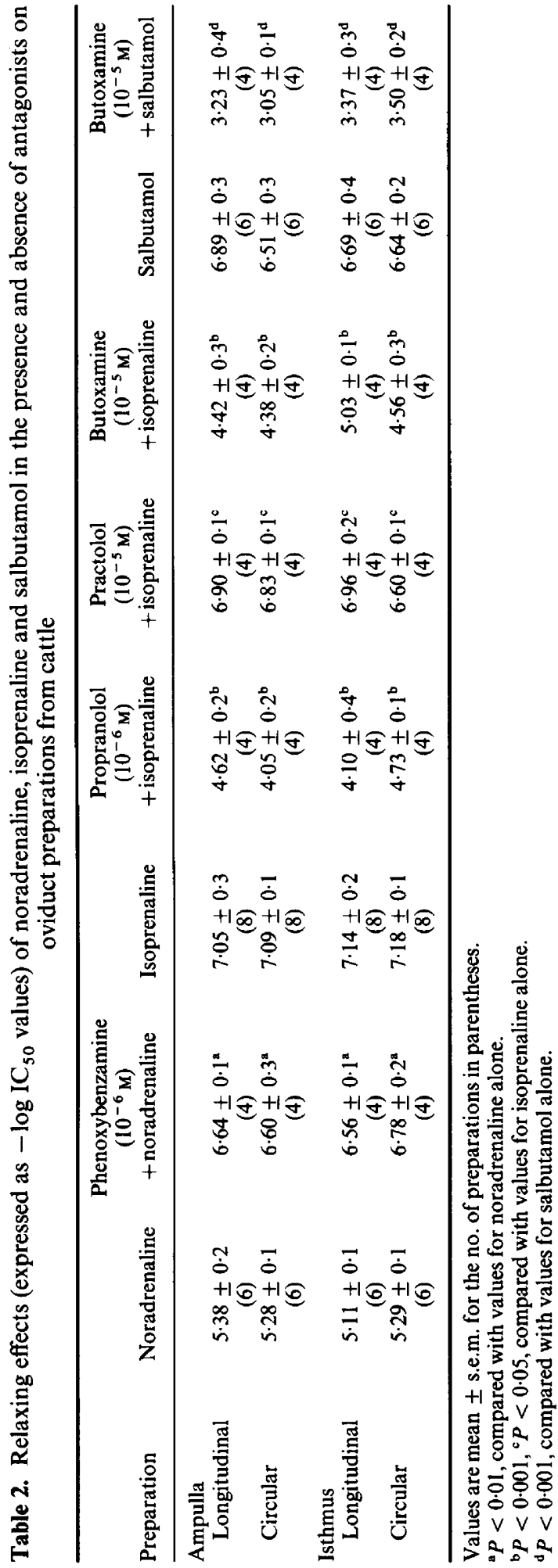


Table 3. Contractile activity (expressed as $-\log \mathrm{EC}_{50}$ values) of noradrenaline and B-HT-920 in the presence and absence of antagonists in oviduct preparations from cattle

\begin{tabular}{|c|c|c|c|}
\hline Preparation & $\begin{array}{c}\text { Propranolol } \\
\left(10^{-6} \mathrm{M}\right)+ \\
\text { noradrenaline }\end{array}$ & B-HT-920 & $\begin{array}{l}\text { Yohimbine } \\
\left(10^{-5} \mathrm{M}\right)+ \\
\text { B-HT-920 }\end{array}$ \\
\hline \multicolumn{4}{|l|}{ Ampulla } \\
\hline Longitudinal & $5 \cdot 21 \pm 0 \cdot 3$ & ${ }_{(6)}^{5 \cdot 50 \pm 0 \cdot 3}$ & $\begin{array}{c}3.05 \pm 0.5^{* * *} \\
(4)\end{array}$ \\
\hline Circular & $5 \cdot 73 \pm 0.3$ & ${ }_{(6)}^{5 \cdot 52} \pm 0 \cdot 2$ & $3 \cdot 26 \pm 0 \cdot 3^{* * *}$ \\
\hline \multicolumn{4}{|l|}{ Isthmus } \\
\hline Longitudinal & $5 \cdot 76 \pm 0.2$ & $5 \cdot 71 \underset{(6)}{ \pm} 0 \cdot 1$ & $3 \cdot 30 \pm 0.0^{* * * *}$ \\
\hline Circular & $5 \cdot 16 \pm 0 \cdot 3$ & $5 \cdot 29 \pm 0 \cdot 1$ & $3.06 \pm 0.4^{* * *}$ \\
\hline
\end{tabular}

Values are mean \pm s.e.m. for the no. of preparations in parentheses.

${ }^{* * *} P<0.001$ compared with other values for that preparation.

It has been argued that the spontaneous activity and sympathomimetic responses of the human tubal smooth muscle vary in relation to different stages of the menstrual cycle, as a reflection of steroid receptor activity (Lindblom et al., 1979a; Batra et al., 1980; Helm et al., 1982a). In our studies, neither quantitative nor qualitative differences in spontaneous contractile activity or reactions to drugs were observed in preparations obtained at different stages of the oestrous cycle in cows. However, this influence should not be excluded because the qualitative method used to classify the oestrous cycle phase does not provide information on accurate hormonal concentrations in the oviduct around the time of ovulation.

Oviducal smooth muscle is a highly excitable tissue that may exhibit spontaneous myogenic activity, and frequency of spike discharge determines the pattern of mechanical activity (Arjamaa, 1982; Bülbring \& Tomita, 1987). In these tissues the mechanical activity is assumed to be caused by the occurrence of action potentials or membrane depolarization (Casteels \& Phil, 1980). According to Bolton (1979), such membrane depolarization will result in an increased influx of $\mathrm{Ca}^{2+}$, leading to an activation of the contractile proteins. This increase of membrane permeability for $\mathrm{Ca}^{2+}$ can be due to the opening of potential-sensitive calcium channels (POCs). These channels open as the potential across the membrane is reduced, and are normally responsible for the upstroke of the action potential in those tissues (highly excitable muscles). Various compounds, the so-called 'calcium channel blockers' (i.e. verapamil), block the entry of $\mathrm{Ca}^{2+}$ mainly through the POCs (Fleckenstein, 1977; Bolton, 1979).

In our experiments $\mathrm{Ca}^{2+}$ withdrawal abolished, in a few minutes, the spontaneous activity. After addition of increasing concentrations of $\mathrm{Ca}^{2+}$, motility was recovered (Fig. 2a), indicating the extracellular $\mathrm{Ca}^{2+}$-dependence of this basal activity. On the other hand, the strong verapamilinduced effect (Fig. 2b) suggests that POCs are involved in the $\mathrm{Ca}^{2+}$ influx supporting the oviducal basal tone.

In this study, both $\alpha$ - and $\beta$-adrenoceptor mediated responses were found in all tubal preparations. Noradrenaline elicited dose-dependent relaxing effects, which were reinforced by prior addition of $\alpha$-adrenergic blockers (Table 2). The fact that noradrenaline evoked relaxation suggests the predominance of $\beta$-adrenoceptors in the oviduct of the cow.

$\beta$-Adrenoceptors in the genital tract are subcategorized as $\beta_{2}$-receptors (Lefkowitz, 1976; Jansen, 1984). The findings of our study show that the isoprenaline-relaxing effect was blocked with propranolol and butoxamine $(P<0.001)$, suggesting a $\beta_{2}$ predominance (Table 2$)$. 
Except for the early reports of Kendle \& Lam Shang Leen (1976), in which a $\beta_{1}$-receptor population was described in the circular muscle layer of the rabbit oviduct, there is no evidence of such receptors in other species. Our results show that practolol ( $\beta_{1}$-adrenoceptor blocker) shifted the $-\log \mathrm{IC}_{50}$ values of isoprenaline significantly $(P<0.05)$ (Table 2$)$. Since noradrenaline is less effective on $\beta_{2}$-receptors (Lands et al., 1967), and the blockade of $\beta$-receptors as well as the $\beta_{1}$-subtype specifically transformed the noradrenaline-induced relaxation into contraction (Table 3; Fig. 3), we suggest that at least a small population of $\beta_{1}$-adrenoceptors should be taken into account in the cattle oviduct.

It has been suggested that both subtypes of $\alpha$-adrenoceptors occur in the human ampullaryisthmic junction, each one predominating during different parts of the menstrual cycle (Helm et al., 1982b). Selective stimulation of $\alpha_{2}$-adrenoceptors, but not those of the $\alpha_{1}$-subtype, mimicked, to the same extent, the noradrenaline-induced responses in the presence of propranolol (Table 3 ). Furthermore, the selective $\alpha_{2}$-antagonist, yohimbine, evoked a significant $(P<0.001)$ blocking effect on the B-HT-920-induced responses. For this reason, we suggest that, in the oviduct of the cow, the $\alpha$-adrenergic component involved in tubal contractility would be the $\alpha_{2}$-subtype. This suggestion differs from that formulated by Helm et al. (1982b), but our studies were conducted only on ampullary and isthmic tissues since there is no morphological evidence of an ampullary-isthmic junction in the cow. Unfortunately, our investigations were not designed to answer the question whether a local adrenergic sphincter, modulated by sex steroids, as suggested for man (Lindblom et al., 1979b; Helm et al., 1982b), could be involved in ovum transport along the cattle oviduct.

Nevertheless $\beta$-adrenergic inhibition was the predominant response of the ampullary and isthmic muscle cells of the cattle oviduct. From a physiological point of view, therefore, the significance of the adrenergic nerves in the cattle oviduct may be to produce relaxation rather than contraction, as Samuelson \& Sjöstrand (1986) pointed out for the human Fallopian tube. In this sense, both human and cattle oviducts differ from the rabbit (Howe \& Black, 1973) and pig (Rodriguez-Martinez, 1984) in which $\alpha$-receptors predominate. These interspecies differences should be considered when general assumptions on the control of fertility are made.

These studies were supported by CAICYT (Project No. 2312-83).

\section{References}

Anand, S. \& Guha, S.K. (1978) Mechanisms of transport of the ovum in the oviduct. Med. Biol. Eng. Comput. 16, 256-261.

Arjamaa, O. (1982) Effect of $\mathrm{Ca}^{2+}$ on the contractility and $\mathrm{Sr}^{2+}$ accumulation in the quail oviductal smooth muscle. Acta physiol. scand. 115, 479-485.

Arjamaa, O. (1984) The effects of stretch on smooth muscle. Gen. Pharmac. 15, 75-77.

Arnold, R. \& Shorey, C.D. (1985) Structure of the oviducal epithelium of the brush-tailed possum (Trichosurus vulpecula). J. Reprod. Fert. 73, 9-19.

Batra, S., Helm, G., Owman, Ch., Sjöberg, N-O. \& Walles, B. (1980) Female sex steroid concentration in the ampullary and isthmic regions of the human Fallopian tube and their relationship to plasma concentrations during the menstrual cycle. Am. J. Obstet. Gynecol. 136, 986-991.

Bolton, T.B. (1979) Mechanisms of action of transmitters and other substances on smooth muscle. Physiol. Rev. 59, 606-718.

Brundin, J. (1965) Distribution and function of adrenergic nerves in the rabbit Fallopian tube. Acta physiol. scand. 66 (Suppl. 259), 1-57.
Bülbring, E. \& Tomita, T. (1987) Catecholamine action on smooth muscle. Pharmacol. Rev. 39, 49-96.

Casteels, R. \& Phil, D. (1980) Electro- and pharmacomechanical coupling in vascular smooth muscle. Chest 78, 150-156.

Fleckenstein, A. (1977) Specific pharmacology of calcium in myocardium, cardiac pacemakers and vascular smooth muscle. Ann. Rev. Pharmacol. Toxicol. 17, 149-166.

Gimeno, M.F., Franchi, A.M., Chaud, M., Gonzalez, E.T., Viggiano, M. \& Gimeno, A.L. (1984) Role of endogenous prostaglandins on the contractile functioning of isolated sow (sus scrofa) oviducts. Prostaglandins 27, 737-752.

Helm, G., Owman, Ch., Sjöberg, N-O. \& Walles, B. (1982a) Motor activity of the human Fallopian tube in vitro in relation to plasma concentrations of oestradiol and progesterone, and the influence of noradrenaline. J. Reprod. Fert. 64, 233-242.

Helm, G., Owman, Ch., Sjöberg, N-O. \& Walles, B. (1982b) Quantitative pharmacological characterization of $\beta$-receptors and two types of $\alpha$-receptors mediating sympathomimetic smooth muscle responses 
in the human Fallopian tube at various cyclic stages. Acta physiol. scand. 114, 425-432.

Howe, G.R. \& Black, D.L. (1973) Autonomic nervous system and oviduct function in the rabbit. I Hormones and contraction. J. Reprod. Fert. 33, 425-430.

Jansen, R.P.S. (1984) Endocrine responses in the Fallopian tube. Endocrine Rev. 5, 525-551.

Kendle, K.E. \& Lam Shang Leen, Y.K. (1976) Further investigation of the response of the mammalian oviduct to catecholamines. J. Reprod. Fert. 46, 231--233.

Lands, A.M., Arnold, A., Mc.Auliff, J.P., Luduena, F.P. \& Brown, T.G. (1967) Differentiation of receptor systems activated by sympathomimetic amines. Nature, Lond. 214, 597-598.

Lefkowitz, R.J. (1976) The $\beta$-adrenergic receptor. Life Sci. 18, 461-472.

Lindblom, B., Hamberger, H. \& Ljung, B. (1979a) Contractile patterns of isolated oviductal smooth muscle under different hormonal conditions. Fert. Steril. 33, 283-287.

Lindblom, B., Ljung, B. \& Hamberger, H. (1979b) Adrenergic and novel non-adrenergic neuronal mechanisms in the control of smooth muscle activity in the human oviduct. Acta physiol. scand. 106, 215-220.
Pauerstein, C.J., Anderson, V., Chatkoff, M.L. \& Hodgson, B.J. (1974) Effect of estrogen and progesterone on the time-course of tubal ovum transport in rabbits. Am. J. Obstet. Gynecol. 120, 299-308.

Rodriguez-Martinez, H. (1984) Effects of adrenergic agents on the in vitro motility of porcine oviducts. Zentbl. VetMed. 31, 91-104.

Rossenberger, G. (Ed.) (1969) Clinical Examination of Cattle. W.B. Saunders, Philadelphia.

Samuelson, U.E. \& Sjöstrand, N.O. (1986) Myogenic and neurogenic control of electrical and mechanical activity in human oviductal smooth muscle. Acta physiol. scand. 126, 355-363.

Schilling, E. (1962) Untersuchungen über den Ban und die Arbeitsweise Eileiters vom Schaf und Rind. Zentbl. VetMed. 9, 805-853.

Verdugo, P., Blandau, R.J., Tam, P.Y. \& Halbert, S.A. (1976) Stochastic elements in the development of determined models of egg transport. In Ovum Transport and Fertility Regulation, pp. 126-137. Eds M. J. K. Harper, C. J. Pauerstein, C. E. Adams, E. M. Coutinho, H. B. Croxatto \& D. M. Paton. Scriptor, Copenhagen.

Received 24 March 1988 